\title{
In Vivo Evaluation of Tectoridin from Puerariae flos on Anti-alcoholism Property in Rats
}

\author{
Qiao-Yun Zhang ${ }^{1}$, Wen Zheng ${ }^{1}$, Shahzor Gul Khaskheli ${ }^{2}$, Wen Huang ${ }^{1, *}$ \\ ${ }^{1}$ College of Food Science and Technology, Huazhong Agricultural University, Wuhan, China \\ ${ }^{2}$ Institute of Food Sciences and Technology, Sindh Agriculture University, Tandojam, Pakistan \\ *Corresponding author: huangwen@mail.hzau.edu.cn
}

Received April 17, 2019; Revised May 22, 2019; Accepted June 17, 2019

\begin{abstract}
Puerariae Flos have developed into one of the improved selling herbal medicines for healing of diseases such as alcohol intoxication and liver injury in China and Japan. Herbal medicines with the multi-targeted and less toxic characteristic have fascinated more attention in the prevention of Alcoholic liver disease ALD. The aim of this study was to investigate the effects of tectorigenin on chemically induced liver fibrosis in rats, Chinese medicine is considered to be an imperative and substitute approach. Tectoridin, naturally extracted from pueraria thunbergiana flos, is commercially acclaimed for its anti-alcoholism function. Furthermore, it was analyzed the effects of tectoridin on sobering the rats up, and to explore the mechanisms of tectoridin from Pueraria thunbergiana Flos sobering the roots up by decreasing the alcohol content, ADH activity in a rat model and the best anti-alcoholism properties among tectoridin, tectorigenin and tectorigenin sodium sulfonate. Acute alcohol poisoning experiment models of rats were set up to evaluate the blood alcohol content in blood and ADH activity in liver. Results showed that tectoridin demonstrated the anti-alcoholism property and a dose of $75 \mathrm{mg} \cdot \mathrm{kg}^{-1} \cdot \mathrm{bw}$ tectoridin showed the strongest clearance rate of ethanol. The comparison of the anti-alcoholism capacity were as follows: tectorigenin sodium sulfonate $(52.86 \%)$ was better than tectoridin $(47.31 \%)(\mathrm{P}<0.01)$ and tectoridin was better than tectorigenin $(43.67 \%)(\mathrm{P}<0.01)$.
\end{abstract}

Keywords: Pueraria Flos extraction, tectorigenin, acute alcohol poisoning, alcohol content, ADH

Cite This Article: Qiao-Yun Zhang, Wen Zheng, Shahzor Gul Khaskheli, and Wen Huang, "In Vivo Evaluation of Tectoridin from Puerariae flos on Anti-alcoholism Property in Rats." Journal of Food and Nutrition Research, vol. 7, no. 6 (2019): 458-464. doi: 10.12691/jfnr-7-6-8.

\section{Introduction}

Alcoholic beverages are widely consumed around the world. Alcohol consumption has both adverse and beneficial effects. The health effects of drinking depend on the quantity and pattern of alcohol consumption.

Alcohol can lead to pregnant women and newborn diseases, cancer, nerve mental disease, cardiovascular disease, liver cirrhosis, accidental damage and active damage on the nervous system, immune system, reproductive system, etc [1]. Every organ and system in the human body is harmed to some degree by alcohol. Medically speaking, the nervous, circulatory and hepato-gastroenterological systems suffer the most damage [2]. The connection between alcohol abuse and liver disease has been known about for centuries. Liver damage can present as a wide range of alcoholic liver diseases: simple liver damage, fatty liver, steatohepatitis, fibrosis, hepatocellular carcinoma, or cirrhosis [3]. The pathogenesis of alcoholic liver damage, one of the big problem in the world, has not been fully elucidated at present, nor does it have a reliable treatment, though many researchers studied on the anti-alcoholism and hepatoprotection properties of different kinds of materials [4]. Melatonin can be effective on anti-alcohol and liver-protection by inhibiting ALT activity and oxidative stress and downregulating MMP-9 regulation in alcohol-induced acute liver [5]. Yong-qian Li first reported that puerariae flos liquor-resolving decoction could facilitate alcohol metabolism in humans. His study indicated that puerariae flos liquor-resolving decoction had an effect on reducing the increase in blood ethanol level after alcohol intake [6]. Previous research found that the extract of puerariae flos had the potential capability of facilitating alcohol metabolism by activating hepatic alcohol dehydrogenase (ADH) which led to the decrease in blood alcohol concentration. Some researchers studied the serological indexes and the oxidoreductase and other indicators in the liver of rats after drinking alcohol, and their results show that flower of puerariae flos have a preventive effect on the alcoholic liver disease by restraining lipid peroxidation, maintaining the intracellular redox equilibrium [7].

The flowers of Pueraria thunbergiana (P. thunbergiana Flos) has been used in traditional Chinese herbal medicine since ancient times to counteract the problems associated with alcohol drinking and liver injury [8]. The herbal medicine contains a variety of isoflavones such as kakkalide, tectoridin and tectorigenin [4]. It is reported 
that the isoflavones of $\mathrm{P}$. thunbergiana Flos showed a wide range of biological activities, including antimutagenic $[9,10]$, hypoglycemic, estrogenic, hypolipidemic, antitumor, hepatoprotective, anticarcinogenic and antioxidant properties [11,12]. The isoflavones in $\mathrm{P}$. thunbergiana Flos are mainly present in the form of their glycosides. Bioavailability of isoflavones differs between glycosides and aglycones [13]. The absorption of isoflavone aglycone is faster than that of isoflavone b-glucoside [14]. Tectoridin (40,5,7-thrihydroxy-6-methoxyisoflavone-7-Ob-D-glucopyranoside), is one of the main isoflavone glycosides in P. thunbergiana Flos and contains one glucosyl moiety. Hydrolysis of the glycosidic bond by intestinal bacteria transforms tectoridin into aglycone - tectorigenin, prior to absorption by intestinal mucosa $[15,16]$. Tectoridin is the main active ingredient of pueraria thunbergiana flos, which has very good medicinal value on protecting liver against alcohol [11,17]. Tectoridin showed more potent hypoglycemic activity, cytotoxicity against tumor cells, hepatoprotective activity and anaphylaxis inhibitory activity than tectoridin $[18,19]$. Tectoridin can remove reactive oxygen species and DPPH in the cell and restrain lipid peroxidation $[18,20]$. Traditional Chinese medicine has been used by almost one-fifth of the world's population since ancient times, and it is an important source of pharmaceutical remedies.

Puerariae flos, the dried flower of Pueraria thomsonii Benth. (Leguminosae), is known to counteract the effects of orally consumed ethanol [1]. The present study was designed to investigate whether the extract of Puerariae flos, In order to understand the pathological mechanism and its capability of anti-alcoholism and hepatoprotection properties of herbal medicines were evaluated by observing and determining a range of indicators.

\section{Materials and Methods}

Puerariae flos, the air-dried flowers of Pueraria thomsonii, was purchased from from Hebei Shengcaotang medicinal materials limited company. Tectoridin, tectorigenin and tectorigenin sodium sulfonate were extracted by the method of [21]. dry flowers of the plant $(1.5 \mathrm{~kg})$ were mixed with $30 \mathrm{~L}$ of boiling water, extracted for $2 \mathrm{~h}$ at $95^{\circ} \mathrm{C}$, and filtered. The filtrate was concentrated and spray drying was carried out to obtain the aqueous extract (400 g).

\subsection{Chemical and Standards}

HWJZ was purchased from Shenzhen Haiwang Health Science and Technology Development Limited Company. Alcalase were purchased from Novozymes Co. (Bagsvaerd, Denmark) Coomassie Brilliant Blue staining detection kits were purchased from Jiancheng Biological Engineering Institute (Nanjing, China). Silymarin Capsules was obtained from MADAUS GmbH (Cologne, Germany). All reagents used were of analytical grade. Standard reagents including n-butyl alcohol, anhydrous n-butyl alcohol, ethanol, anhydrous ethanol, acetone, 95\% of medical alcohol, methanol ethyl acetate, were purchased from sinopharm chemical reagent Co. Ltd (Beijing, China).

\subsection{Animals and Treatments}

Male SPF KM rats weighing $18 \pm 22 \mathrm{~g}$, were purchased from Wuhan Institute of Biological Products Limited Liability Company (eligible certificate number: SCXK 2012-0003). Ten rats were housed in a cage in an animal room, and their living environment were clean with fresh air and well ventilated $8-12$ times per hour, and the living temperature were between $18-22{ }^{\circ} \mathrm{C}$ and relative humidity of $50 \sim 60 \%$ and the noise below 85 decibels. All rats were offered with standard feed and free access to water and acclimatized for one week before commencement of experiment.

\subsection{Instrumentation}

The following instruments were occupied: rotary evaporator model RE-2000A (Yarong Bio-instrument Shanghai, China) spectrophotometer (ZW0310072703 Shanghai, China), Autoclave (Model-YX 280 A, Shanghai, China, gas chromatograph model 6890 (Agilent Technologies, USA) fitted with a HP-5 Silica capillary column $(30 \mathrm{~m} \times 0.32 \times 0.5 \mathrm{um})$ and a flame ionization detector (FID).

\subsection{Acute Alcohol Toxicity Experiments of Tectoridin on Rats}

\subsubsection{Determination of the Effect of Tectoridin on Anti-alcoholism Property}

30 SPF rats were divided into 5 groups alcohol group, control group $\left(\mathrm{HWJZ}, 400 \mathrm{mg} \cdot \mathrm{kg}^{-1} \cdot \mathrm{bw}\right)$ and tectoridin groups $\left(5,100,400 \mathrm{mg} \cdot \mathrm{kg}^{-1} \cdot \mathrm{bw}\right)$, each group consist of 6 rats. One week later, they were limited to food but water and more than $12 \mathrm{~h}$ later, alcohol group were fed with water, control group were induced by $400 \mathrm{mg} \cdot \mathrm{kg}^{-1} \cdot \mathrm{bw}$ HWJZ whereas the tectoridin groups received different concentrations of tectoridin solution. Followed by 30mins later, all groups nourished $50 \%$ alcohol with the concentration of $0.3 \mathrm{ml} / 25 \mathrm{~g}$ and leave for one hour. Subsequently to $1 \mathrm{~h}$ later they were slaughtered and their blood used to measure the alcohol content and livers for ADH.

\subsubsection{Determination of the Best Tectoridin Concentration to Anti-alcoholism Property}

110 SPF rats were divided into blank control group, alcohol group, control group $\left(\mathrm{HWJZ}, 400 \mathrm{mg} \cdot \mathrm{kg}^{-1} \cdot \mathrm{bw}\right)$ and 8 tectoridin groups $(25,50,75,100,125,150,250$ and $\left.400 \mathrm{mg} \cdot \mathrm{kg}^{-1} \cdot \mathrm{bw}\right), 10$ rats in each group. After one week's conventional breeding, they were limited to food but water for more than $12 \mathrm{~h}$. Then alcohol group were fed with water, and control group were induced by $400 \mathrm{mg} \cdot \mathrm{kg}^{-1} \cdot \mathrm{bw}$ HWJZ whereas the tectoridin groups received the corresponding different concentrations of tectoridin solution $\left(25,50,75,100,125,150,250\right.$ and $\left.400 \mathrm{mg} \cdot \mathrm{kg}^{-1} \cdot \mathrm{bw}\right)$. Followed by $30 \mathrm{mins}$ later, all groups were given medicine through administration by gavage with $50 \%$ alcohol at the concentration of $0.3 \mathrm{ml} / 25 \mathrm{~g}$, then leave all the rats for one hour. Subsequently to $1 \mathrm{~h}$ later they were slaughtered and the alcohol content in blood and ADH activity in livers were measured. 


\subsubsection{Determination of the Best Anti-alcoholism Properties among Tectoridin, Tectorigenin and Tectorigenin Sodium Sulfonate}

60 SPF rats were divided into 6 groups: normal group, alcohol group, control group(HWJZ,400 $\left.\mathrm{mg} \cdot \mathrm{kg}^{-1} \cdot \mathrm{bw}\right)$, tectoridin group $\left(75 \mathrm{mg} \cdot \mathrm{kg}^{-1} \cdot \mathrm{bw}\right)$, tectorigenin group $\left(75 \mathrm{mg} \cdot \mathrm{kg}^{-1} \cdot \mathrm{bw}\right)$ and tectorigenin sodium sulfonate group $\left(75 \mathrm{mg} \cdot \mathrm{kg}^{-1} \cdot \mathrm{bw}\right)$, each group consist of 10 rats. One week later, they were limited to food but water and more than $12 \mathrm{~h}$ later, alcohol group were fed with water, control group were induced by $400 \mathrm{mg} \cdot \mathrm{kg}^{-1} \cdot \mathrm{bw} \mathrm{HWJZ}$ whereas the tectoridin group, tectorigenin group and tectorigenin sodium sulfonate group received the same concentration (75 $\mathrm{mg} \cdot \mathrm{kg}^{-1} \cdot \mathrm{bw}$ ) of tectoridin solution, tectorigenin solution and tectorigenin sodium sulfonate solution. 30 mins later, all groups nourished 50\% alcohol with the concentration of $0.3 \mathrm{ml} / 25 \mathrm{~g}$ and leave for one hour. Subsequently to $1 \mathrm{~h}$ later they were slaughtered and their blood used to measure the alcohol content and livers for $\mathrm{ADH}$.

\subsection{Gas Chromatography Test Conditions}

Chromatographic column, DL-Wax capillary-column chromatography $30.0 \mathrm{~m} \times 320 \mathrm{~mm} \times 0.25$ um; Detector: FID detector, temperature: $280^{\circ} \mathrm{C}$; Flow rate: Hydrogen $33 \mathrm{ml} / \mathrm{min}$, air $400 \mathrm{ml} / \mathrm{min}$ and nitrogen $30 \mathrm{ml} / \mathrm{min}$; Temperature programme: $50^{\circ} \mathrm{C}, 8^{\circ} \mathrm{C} / \mathrm{min}$ up to $80^{\circ} \mathrm{C}$ for $1 \mathrm{~min}, 20^{\circ} \mathrm{C} / \mathrm{min}$ up to $220^{\circ} \mathrm{C}$ for $1 \mathrm{~min}$.

\subsection{Determination of ADH in Livers}

ADH enzyme activity was determined by Vallee \& Hoch:

ADH activity $(\mathrm{U} / \mathrm{mg})=\mathrm{E} 340 \times 3.1 / 6.2 \mathrm{Ew}$

E340 increase of absorbance values every $10 \mathrm{~s}$ at $340 \mathrm{~nm}$

Ew — per milliliter of enzyme solution in a bath containing an enzymatic, weight (mg)

6.2 the molar absorption coefficient of NADH

3.1 the volume of the test solution

\subsection{Pathology Inspection of the Liver Organization}

The liver was fixed with $10 \%$ paraformaldehyde solution, embedded with paraffin and sectioned and stained with HE.Observed the changes of liver tissue under light microscope. Record the result of the experiment by the microscopic image processing apparatus.

\subsection{Statistical Analysis}

Data were calculated and significance differences were found out using analysis of variance (ANOVA). Statistical significance was established at $p<0.05$, using the software package SPSS (IBM Statistics version 20).

\section{Result and Discussion}

Up to our knowledge no reports have discussed on the protective effect of Puerariae flos, although preparations of this plant have been used in the traditional Chinese herbal medicine to counteract the effects of alcohol consumption. In the present study we found that thomsonide, an extract of Puerariae flos, as well as teprenone, had a protective effect against ethanol-induced gastric mucosal lesions. Puerariae and Flos Puerariae, have been used for centuries in China to relieve intoxication and hangover from excessive drinking.

\section{Alcohol Concentration in Blood and ADH Activity in Livers Reflecting Anti-alcoholism Property of \\ Tectoridin}

ADH mainly exists in the liver cells, while very few in other cells. ADH can promote ethanol metabolism in the liver cells, removing blood alcohol. Higher activity of ADH reflects better anti-alcoholism properties [22,23,24]. The results for the tectoridin on alcohol concentration were shown in Table 1. Decrease of alcohol content in blood and increase of liver ADH activity were observed in HWJZ-positive group and tectoridin I, II, III $(\mathrm{P}<0.01)$ as compared with alcohol and control group, indicating that tectoridin had an positive effect on anti-alcoholism properties in experimental rats, especially at the dose of $100 \mathrm{mg} \cdot \mathrm{kg}^{-1} \cdot \mathrm{bw}$. The anti-alcoholism properties of tectoridin group at the dose of $100 \mathrm{mg} \cdot \mathrm{kg}^{-}$ ${ }^{1}$. bw was most close to that of HWJZ-positive group, indicating that $100 \mathrm{mg} \cdot \mathrm{kg}^{-1} \cdot \mathrm{bw}$ tectoridin treatment to rats had the similar efficacy to $400 \mathrm{mg} \cdot \mathrm{kg}^{-1} \cdot \mathrm{bw}$ HWZJ treatment. The results indicted that a dose of tectoridin around $100 \mathrm{mg} \cdot \mathrm{kg}^{-1} \cdot \mathrm{bw}$ possesses the strongest ability to eliminate alcohol content in blood and enhance $\mathrm{ADH}$ activity in liver.

Table 1. Changes of Alcohol Concentration in Blood and ADH Activity in Livers

\begin{tabular}{|c|c|c|c|c|}
\hline Group & Dose & Alcohol content $(\mu \mathrm{L} / \mathrm{MI})$ & Alcohol clearance $(\%)$ & ADH activity (U/g) \\
\hline control group & - & $0 \pm 0.00$ & - & $21.46 \pm 2.84 \mathrm{~A}$ \\
\hline alcohol group & $12 \mathrm{ml} / \mathrm{kg}$ bw, $50 \%$ alcohol & $4.64 \pm 0.24 \mathrm{~A}$ & - & $25.31 \pm 3.01 \mathrm{~A}$ \\
\hline Tectoridin & $5 \mathrm{mg} / \mathrm{kg} . \mathrm{bw}$ tectoridin $+12 \mathrm{ml} / \mathrm{kg}$ bw $50 \%$ alcohol & $4.05 \pm 0.09 \mathrm{~B}$ & 12.72 & $29.84 \pm 3.25 \mathrm{~B}$ \\
\hline Tectoridin & $100 \mathrm{mg} / \mathrm{kg} . \mathrm{bw}$ tectoridin $+12 \mathrm{ml} / \mathrm{kg}$ bw $50 \%$ alcohol & $2.99 \pm 0.10 \mathrm{C}$ & 35.56 & $45.48 \pm 3.79 \mathrm{C}$ \\
\hline Tectoridin & $400 \mathrm{mg} / \mathrm{kg} . \mathrm{bw}$ tectoridin $+12 \mathrm{ml} / \mathrm{kg}$ bw $50 \%$ alcohol & $4.29 \pm 0.10 \mathrm{~A}$ & 7.54 & $31.06 \pm 4.13 \mathrm{~B}$ \\
\hline HWJZ & $400 \mathrm{mg} / \mathrm{kg} . \mathrm{bw} \mathrm{HWJZ}+12 \mathrm{ml} / \mathrm{kg}$ bw $50 \%$ alcohol & $2.89 \pm 0.09 \mathrm{C}$ & 37.72 & $50.68 \pm 4.72 \mathrm{D}$ \\
\hline
\end{tabular}

Note: Groups with different capital letters in the same column value have a very significant difference $(\mathrm{P}<0.01)$. 
Table 2. Different Changes of Alcohol Concentration and ADH Activity

\begin{tabular}{|c|c|c|c|c|}
\hline Group & Dose & Alcohol concent $(\mu \mathrm{L} / \mathbf{m L})$ & Alcohol clearance $(\%)$ & ADH activity (U/g) \\
\hline control group & - & $0 \pm 0.00$ & - & $21.46 \pm 2.84 \mathrm{~A}$ \\
\hline alcohol group & $12 \mathrm{ml} / \mathrm{kg} \cdot \mathrm{bw} 50 \%$ alcohol & $4.67 \pm 0.75 \mathrm{~A}$ & - & $23.52 \pm 2.15 \mathrm{~A}$ \\
\hline HWJZ & $400 \mathrm{mg} / \mathrm{kg} \cdot \mathrm{bw} \mathrm{HWJZ}+12 \mathrm{ml} / \mathrm{kg} \cdot$ bw $50 \%$ alcohol & $2.90 \pm 0.41 \mathrm{~B}$ & 37.90 & $45.46 \pm 2.53 \mathrm{~B}$ \\
\hline Tectoridin & $25 \mathrm{mg} / \mathrm{kg} \cdot \mathrm{bw}$ tectoridin $+12 \mathrm{ml} / \mathrm{kg} \cdot \mathrm{bw} 50 \%$ alcohol & $2.95 \pm 0.92 \mathrm{~B}$ & 37.90 & $39.25 \pm 3.03 \mathrm{C}$ \\
\hline Tectoridin & $50 \mathrm{mg} / \mathrm{kg} \cdot \mathrm{bw}$ tectoridin $+12 \mathrm{ml} / \mathrm{kg} \cdot \mathrm{bw} 50 \%$ alcohol & $2.65 \pm 0.45 \mathrm{C}$ & 43.25 & $46.35 \pm 2.92 B$ \\
\hline Tectoridin & $75 \mathrm{mg} / \mathrm{kg} \cdot \mathrm{bw}$ tectoridin $+12 \mathrm{ml} / \mathrm{kg} \cdot \mathrm{bw} 50 \%$ alcohol & $2.29 \pm 0.25 \mathrm{C}$ & 50.96 & $51.64 \pm 3.84 \mathrm{D}$ \\
\hline Tectoridin & $100 \mathrm{mg} / \mathrm{kg} \cdot \mathrm{bw}$ tectoridin $+12 \mathrm{ml} / \mathrm{kg} \cdot \mathrm{bw} 50 \%$ alcohol & $2.96 \pm 0.23 \mathrm{~B}$ & 36.62 & $34.82 \pm 2.47 \mathrm{E}$ \\
\hline Tectoridin & $125 \mathrm{mg} / \mathrm{kg} \cdot \mathrm{bw}$ tectoridin $+12 \mathrm{ml} / \mathrm{kg} \cdot \mathrm{bw} 50 \%$ alcohol & $3.29 \pm 1.28 \mathrm{D}$ & 29.55 & $31.96 \pm 2.12 \mathrm{E}$ \\
\hline Tectoridin & $150 \mathrm{mg} / \mathrm{kg} \cdot \mathrm{bw}$ tectoridin $+12 \mathrm{ml} / \mathrm{kg} \cdot \mathrm{bw} 50 \%$ alcohol & $3.49 \pm 1.24 \mathrm{~A}$ & 25.27 & $29.83 \pm 2.17 \mathrm{E}$ \\
\hline Tectoridin & $250 \mathrm{mg} / \mathrm{kg} \cdot \mathrm{bw}$ tectoridin $+12 \mathrm{ml} / \mathrm{kg} \cdot$ bw $50 \%$ alcohol & $4.29 \pm 0.49 \mathrm{~A}$ & 8.14 & $22.15 \pm 2.95 \mathrm{~A}$ \\
\hline Tectoridin & $400 \mathrm{mg} / \mathrm{kg} \cdot \mathrm{bw}$ tectoridin $+12 \mathrm{ml} / \mathrm{kg} \cdot \mathrm{bw} 50 \%$ alcohol & $4.35 \pm 2.02 \mathrm{~A}$ & 6.85 & $24.76 \pm 3.68 \mathrm{~F}$ \\
\hline
\end{tabular}

\subsection{Determination of the Best Dosage of Tectoridin}

Decreases of alcohol content in blood and increases of liver ADH activity can be observed in HWJZ-positive group and all tectoridin groups $(\mathrm{P}<0.01)$, as compared with alcohol group (Table 2). The ADH activity of tectoridin group of $75 \mathrm{mg} \cdot \mathrm{kg}^{-1} \cdot \mathrm{bw}$ was the highest and the alcohol content in blood was the lowest in all groups in Table 2 while the HWJZ-positive group ranked second. The ability of tectoridin clearing the ethanol decreased in Tectoridin V, Tectoridin VI, Tectoridin VII and Tectoridin VIII, compered with other groups, the dose of $400 \mathrm{mg} \cdot \mathrm{kg}^{-1} \cdot \mathrm{bw}$ tectoridin reaching the lowest (Table 2). This was in agreement with the investigation of other researchers that the extract of puerariae flos had the potential capability of facilitating alcohol metabolism by activating hepatic alcohol dehydrogenase (ADH) which led to the decrease in blood alcohol concentration [25,26,27].

The results indicated that a dose of $75 \mathrm{mg} \cdot \mathrm{kg}^{-1} \cdot \mathrm{bw}$ of tectoridin showed the strongest clearance rate of ethanol compared with other groups and it is better to intake a tectoridin concentration of $50 \mathrm{mg} \cdot \mathrm{kg}^{-1} \cdot \mathrm{bw}$ to $100 \mathrm{mg} \cdot \mathrm{kg}^{-1} \cdot \mathrm{bw}$ for the drunken rats, while too much high concentration of tectoridin showed little effect on clearing ethanol concentration in rats' blood.

\subsection{GC Chromatography}

Figure 1 showed GC chromatogram of different groups of rats, and the peak area of ethanol and n-butyl alcohol in ethanol model group showed a significant increase compared with that in standard sample group. A significant decrease was observed in the peak area of ethanol and n-butyl alcohol in HWJZ group and different concentrations of tectoridin groups, compared to that of ethanol model group, clearly stating that tectoridin and HWJZ can reduce the content of alcohol in blood and the tectoridin group of $75 \mathrm{mg} \cdot \mathrm{kg}^{-1} \cdot \mathrm{bw}$ showed better anti-alcoholism property than that of $400 \mathrm{mg} \cdot \mathrm{kg}^{-1} \cdot \mathrm{bw}$ of HWJZ, indicating that the anti-alcoholism property of tectoridin was better than HWJZ. The results were in accordance with the research $[28,29]$ that thunbergiana Flos and the extract of it could better wake up the rats from drunken state to awake for their abilities to clear the alcohol content.

\subsection{Determination of the Best Anti- alcoholism Properties among Tectoridin, Tectorigenin and Tectorigenin Sodium Sulfonate}

As showed in Table 3, the alcohol content in blood of HWJZ, tectoridin, tectorigenin and tectorigenin sodium sulfonate groups showed a significant difference $(\mathrm{P}<$ 0.01)compared with that of alcohol group, and the decrease of alcohol content indicated the anti-alcoholism properties in these groups.

A significant decrease $(\mathrm{P}<0.01)$ of alcohol content in tectoridin, tectorigenin and tectorigenin sodium sulfonate groups was observed compared with that of HWJZ group, indicating that the anti-alcoholism properties of tectoridin, tectorigenin and tectorigenin sodium sulfonate were better than that of HWJZ; A significant difference can also be observed $(\mathrm{P}<0.01)$ among tectoridin, tectorigenin and tectorigenin sodium sulfonate group, and according to the alcohol clearance, we can draw a conclusion that the antialcoholism property of tectorigenin sodium sulfonate $(52.86 \%)$ was the best, followed by tectoridin $(47.31 \%)$ and tectorigenin $(43.67 \%)$. The results are agree with $[30,31]$, the physical and chemical properties and biological activity of tectoridin, tectorigenin and tectorigenin sodium sulfonate were different from each other. As for the physical and chemical properties, the factor of water soluble was one of the main factors. In the study of $[32,33]$, they studied the physical and chemical properties of tectoridin, tectorigenin and tectorigenin sodium sulfonate, finding the solubility of tectoridin, tectorigenin and tectorigenin sodium sulfonate were as follows: $142.96 \pm 6.01 \mathrm{ug} / \mathrm{ml}, 125.91 \pm 3.72 \mathrm{ug} / \mathrm{ml}$ and $1168.48 \pm 9.74 \mathrm{ug} / \mathrm{ml}$ $[34,35]$. A sulfo was added to tectorigenin, enhancing the hydrophilic of tectorigenin sodium sulfonate (about 9 times stronger than that of tectorigenin), making the availability improved ,thus, better for anti-alcoholism property; As for biological activity [36,37], in vitro antioxidant activities were studied and the results showed that the antioxidant capacity in anti lipid peroxidation, reducing power and removing the ultra oxygen anion, DPPH and hydroxyl radicals were as follows: tectorigenin sodium sulfonate was better than tectorigenin and tectorigenin was better than tectoridin. These studies were similar to the observation of our results $[38,39,40]$. 

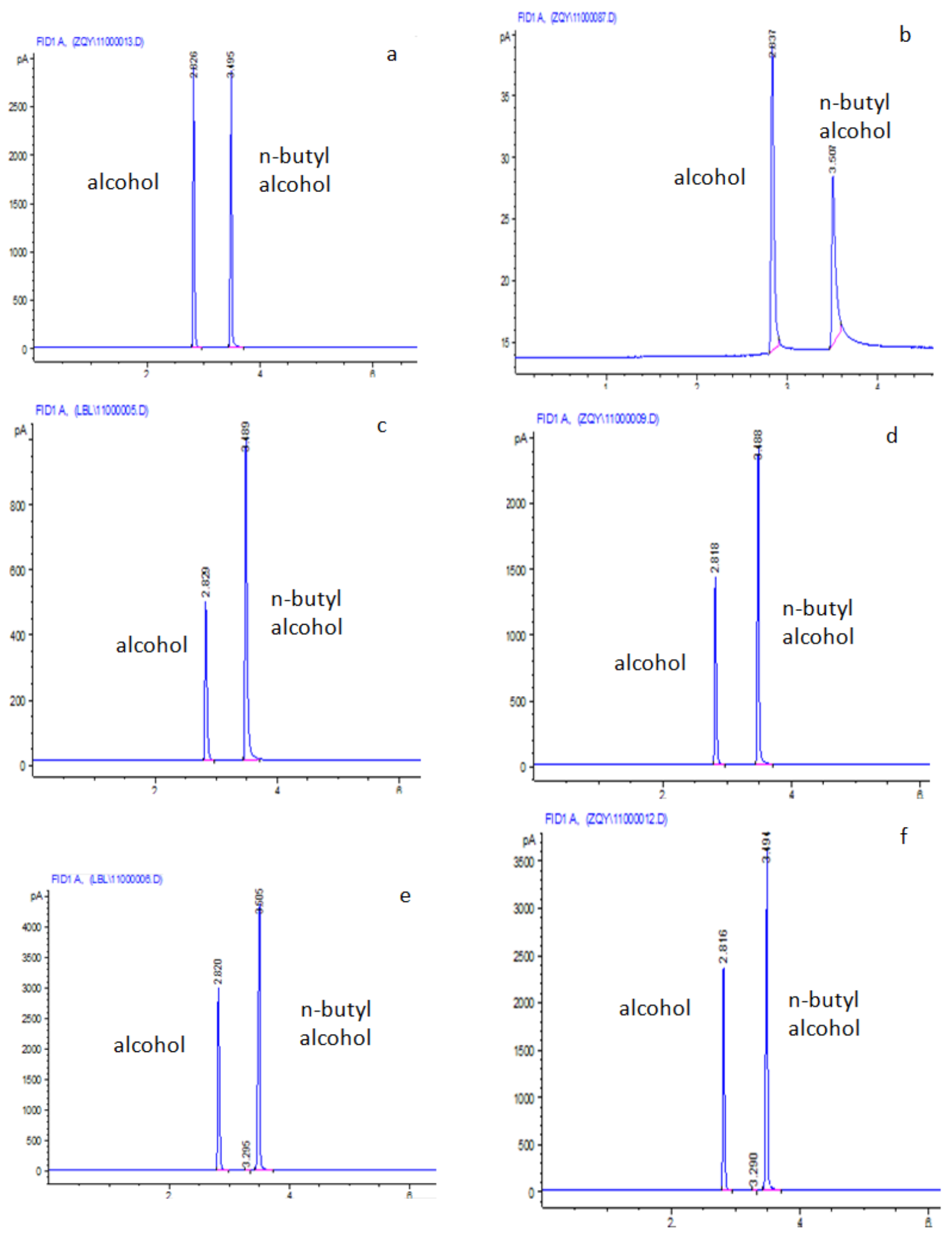

Figure 1. Showed GC chromatogram of different groups of rats, and the peak area of ethanol and n-butyl alcohol

Table 3. The Blood Alcohol Concentration of Tectoridin, Tectorigenin and Tectorigenin Sodium Sulfonate on Rats

\begin{tabular}{|c|c|c|c|}
\hline Group & Dose & Alcohol content $(\mu \mathrm{L} / \mathbf{m L})$ & Alcohol clearance (\%) \\
\hline control group & - & 0 & - \\
\hline alcohol group & $12 \mathrm{ml} / \mathrm{kg}$ bw, $50 \%$ alcohol & $5.77 \pm 0.58 \mathrm{~A}$ & - \\
\hline HWJZ & $400 \mathrm{mg} / \mathrm{kg} . \mathrm{bw} \mathrm{HWJZ}+12 \mathrm{ml} / \mathrm{kg}$ bw $50 \%$ alcohol & $3.83 \pm 0.54 \mathrm{~B}$ & 33.62 \\
\hline Tectoridin & $75 \mathrm{mg} / \mathrm{kg} . \mathrm{bw}$ tectoridin $+12 \mathrm{ml} / \mathrm{kg}$ bw $50 \%$ alcohol & $3.04 \pm 0.34 \mathrm{C}$ & 47.31 \\
\hline Tectorigenin & $75 \mathrm{mg} / \mathrm{kg} . \mathrm{bw}$ tectorigenin $+12 \mathrm{ml} / \mathrm{kg}$ bw $50 \%$ alcohol & $3.25 \pm 0.45 \mathrm{D}$ & 43.67 \\
\hline $\begin{array}{l}\text { Tectorigenin sodium } \\
\text { sulfonate }\end{array}$ & $\begin{array}{l}75 \mathrm{mg} / \mathrm{kg} . \mathrm{bw} \text { tectorigenin sodium sulfonate }+12 \mathrm{ml} / \mathrm{kg} \\
\text { bw } 50 \% \text { alcohol }\end{array}$ & $2.72 \pm 0.81 \mathrm{E}$ & 52.86 \\
\hline
\end{tabular}




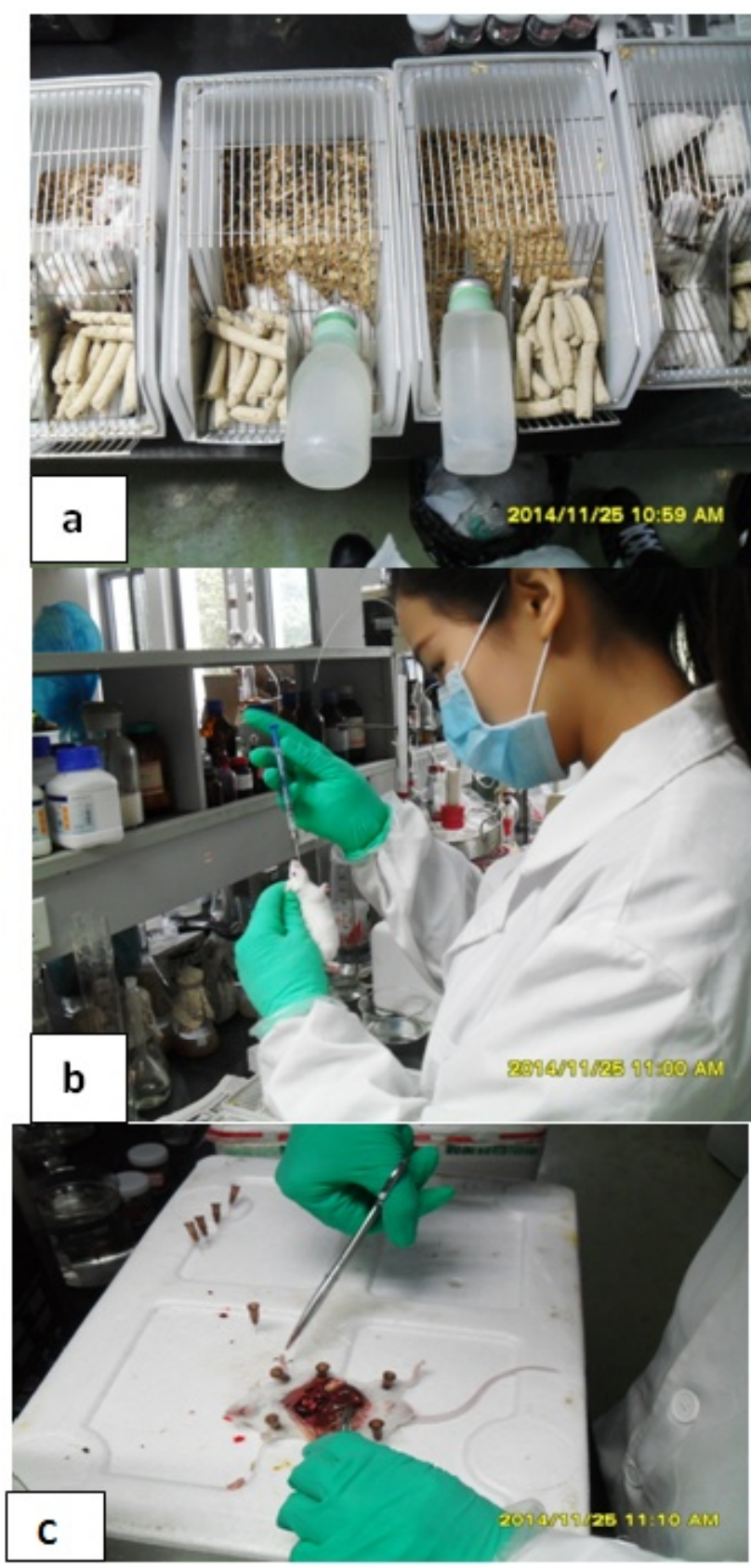

Figure 2.

\section{Conclusions}

Extract of Puerariae flos, has been investigated for its effect on ethanol on anti-alcoholism property in rats. Chinese Herbal medicines have been used since ancient time. In results of this study showed that tectoridin from Pueraria flos has a certain prevention effect on anti-alcoholism and a dose of $75 \mathrm{mg} \cdot \mathrm{kg}^{-1} \cdot \mathrm{bw}$ tectoridin showed the strongest clearance rate of ethanol and it is better to intake a tectoridin concentration of $50 \mathrm{mg} \cdot \mathrm{kg}$ ${ }^{1} \cdot \mathrm{bw}$ to $100 \mathrm{mg} \cdot \mathrm{kg}^{-1} \cdot \mathrm{bw}$ for the drunken rats, while too much high concentration of tectoridin showed little effect on clearing ethanol concentration; The anti-alcoholism properties of tectoridin, tectorigenin and tectorigenin sodium sulfonate were better than that of HWJZ and we can draw a conclusion that the anti-alcoholism property of tectorigenin sodium sulfonate $(52.86 \%)$ was the best, followed by tectoridin(47.31\%)and tectorigenin(43.67\%). This study discussed the anti-alcoholism property of tectoridin, but the hepatoprotection of how it works is unknown, so further more studies from aspects such as lipid peroxidation, oxidative stress and gene should be carried out in future study.

\section{Acknowledgements}

The authors are grateful for the financial support from the National Natural Science Foundation of China (No. 31071499) and the Special Fund for Nonprofit Research in Hubei Province (No. 2013BBB11).

\section{References}

[1] Urashima, S., Tsutsumi, M., Shimanaka, K. Histochemical study of hyaluronate in alcohol liver disease. Alcoholism-clinical and Experimental Research 23, 568-608. 2009.

[2] Testino, G. Alcoholic diseases in hepato-gastroenterology: a point of view. Hepato- gastroenterology 55, 371-377. 2008.

[3] Crabb, D.W. Ethanol oxidizing enzymes: roles in alcohol metabolism and alcoholic live disease. Prog Liver Dis 13, 151-172. 1995.

[4] Kim, C., Shin, S., Ha, H., Kim, J.M. Study of substance changes in flowers of Pueraria thunbergiana Benth during storage. Archives of Pharmacal Research 26, 210-213. 2003.

[5] Bilbao-Sainz et al "Hydration kinetics of dried apple as affected by drying condion Journal of Food Engineering. 68, 369-376. 2005.

[6] Akkemik, E., Sellturk, M., Ozgeris,F.B. In vitro effects of some drugs on human erythrocyte glutathione reductase. Turkish Journal of Medical Sciences 41, 235-241. 2011.

[7] Diesen, D.L., Kuo, P.C. Nitric oxide and redox regulation in the liver: Part II. Redox biology in pathologic hepatoeytes and implications for Intervention. Journal of Surgical Research 167, 96-112. 2011

[8] Shin, J., Bae, E.A., Lee, Y.C., Ma, J.Y., Kim, D.H. Estrogenic effect of main components kakkalide and tectoridin of puerariae flos and their metabolites. Biological \& Pharmaceutical Bulletin 29, 1202-1206. 2006.

[9] Keung, W.M., Vallee, B.L. Kudzu root: an ancient Chinese source of modern antidipsortopic agents. Phytochemistry 47, 499-506. 1998.

[10] Lee, K.T., Sohn, C., Kim, D.H., Choi, J.W., Kwon, S.H., Park, H.J. Hypoglycemic and hypolipidemic effects of tectorigenin and kaikasaponin III in the streptozotocin-induced diabetic rat and their antioxidant activity in xitro. Arch Pharm Res 23, 461-466. 2000.

[11] Lee, K.T., Sohn, I.C., Kim, Y.K., Choi, J.H., Choi, J.W., Park, H.J., Itoh, Y., Miyamoto, K.I. Tectorigenin, an isoflavone of Pueraria thunbergiana BENTH., induces differentiation and apoptosis in human promyelocytic leukemia HL-60 cells. Biological and Pharmaceutical Bulletin 24, 1117-1121. 2001.

[12] Park, H.J., Park, J.H., Moon, J.O., Lee, K.T., Jung, W.T., Oh, S.R., Lee, H.K. Isoflavone glysides from the flowers of Pueraria Thurbergiana. Phytochemistry 51, 147-151. 1999.

[13] Park, K.Y., Jung, G.O., Choi, J., Lee, K.T., Park, H.J. Potent antimutagenic and their anti-lipid peroxidative effect of kaikasaponin III and tectorigenin from the flower of Pueraria thunbergiana. Archives of Pharmacal Research 25, 320-324. 2002.

[14] King, R.A., Broadbent, J.L., Head, R.J. Absorption and excretion of the soy isoflavone genistein in rats. Journal of Nutrition 126, 176-182. 1996.

[15] Izumi, T., Piskula, M.K., Obata, A., Tobe, K., Satito, M. Soy isoflavone aglycones are absorbed faster and in higher amounts than their glucosides in humans. Journal of Nutrition 130, 1695-1699. 2000.

[16] Bae, E.A., Han, M.J., Lee, K.T., Choi, J.W., Park, H.J., Kim, D.H. Metabolism of 6"-O-xylosyltectoridin and tectoridin by human intestinal bacteria and their hypoglycemic and in vitro cytotoxic 
activities. Biological \& Pharmaceutical Bulletin 22, 1314-1318. 1999.

[17] Park, E.K., Shin, Y.W., Lee, H.U., Lee, C.S., Kim, D.H. Passive cutaneous anaphylaxis-inhibitory action of tectorigenin, a metabolite of tectoridin by intestinal microflora. Biological \& Pharmaceutical Bulletin 27, 1099-1102. 2004.

[18] Nohara, T., Kinjo, Y., Nakajima, K. The new isoflavoid of Pueraria lobata. Kokai Tokkyo Koho 694, 17-07. 2000.

[19] Kang, K.A., Lee, K.H., Chae, S., Zhang, R., Jung, M.S., Kim, S.Y., Kim, H.S., Kim, D.H., Hyun, J. V.V. Cytoprotective effect of tectorigenin, a metabolite formed by transformation of tectoridin by intestinal microflora, on oxidative stress induced by hydrogen peroxide. European journal of pharmacology 519, 16-23. 2005.

[20] Tsuchihashi, R., Kodera, M., Sakamoto, S., Nakajima, Yamazaki T., Niiho, Y., Nohara, T., Kinjo, J. Microbial transformation and bioactivation of isoflavones from Pueraria flowers by human intestinal bacterial strains. Journal of Natural Medicines 63, 254-260. 2009

[21] Kang, K.A., Zhang, R., Piao, M.J. Protective effect of irisolidone, a metabolite of kakkalide, against hydrogen peroxide induced cell damage via antioxidant effect. Bioorganic and Medicinal Chemistry 16, 1133-1141. 2008.

[22] Zhang, Y.D., Huang, W. Study on isolation, purifieation, identifieation of structure of the isoflavones from puerariae flos. Processing and Storage of Agricultural Products 321, 105-274. 2009.

[23] Lee, K.T., Sohn, C., Kim, Y.K., Choi, J.H., Choi, J.W., Park, H.J., Itoh, Y., Miyamoto, K. Tectorigenin, an isoflavone of Pueraria thunbergiana Benth., induces differentiation and apoptosis in human promyelocytic. Biological \& Pharmaceutical Bulletin 24 1117-1121. 2001.

[24] Mishra, A., Paul, S., Swarnakar, S. Downregulation of matrix metalloproteinase- 9 by melatonin during prevention of alcohol-induced liver injury in mice. Biochimie 93, 854-866. 2011.

[25] Mattef, K., Laissue, J.A. Copper/zinc and manganese superoxide dismutases in alcoholic liver disease: Immunohistochemical quantitation. Histology and Histopathology 11, 899-907. 2005.

[26] Nuviala, R.J., Roda, L., Lapieza, M.G. Serum enzymes activities at rest and after a marathon race. Journal of Sports Medicine and Physical Fitness 32, 180-186. 1992.

[27] Lee, K.T., Sohn, C., Kim, D.H., Choi, J.W., Kwon, S.H., Park, H.J. Hypoglycemic and hypolipidemic effects of tectorigenin and kaikasaponin III in the streptozotocin-induced diabetic rat and their antioxidant activity in vitro. Archives of Pharmacal Research 23, 461-466. 2000
[28] Kim, C., Shin, S., Ha, H., Kim, J.M. Study of substance changes in flowers of pueraria thunbergiana (Benth.) during storage. Archives of pharmacal research 26, 210-213. 2003.

[29] Albano, E. Free radical mechanisms in immune reactions associated with alcoholic disesase. Free Radical Biology and Medicine 32, 110-114. 2002.

[30] Crabb, D.W. Ethanol oxidizing enzymes: roles in alcohol metabolism and alcoholic live disease. Prog Liver Dis 13, 151-172. 1995.

[31] Sadzuka, Y., Sugiyama, T., Nagamine, M. Efficacy of theanine is conneeted with theanine metabolism by any enzyme, not only drug metabolizing enzymes. Food and Chemical Toxicology 44, 286-292. 2006.

[32] Guo, H., He, H., Han, Y., Huang, W.H., Zhang, X.O. Effect of corn peptides on alcohol dehydrogenase activity in live of mice after drinking and its anti-alcohol mechanism. Food Science 11, 0265-05. 2011.

[33] Szuster-Ciesielska, A., Daniluk, J., Kandefer-Szerszen, M. Oxidative stress in the blood of patients with alcohol-related liver cirrhosis. Med Sci Monit 8, 419-24. 2002.

[34] Seo, H.J., Jeong, K.S., Lee, M.K. Role of naringin supplement in regulation of lipid and ethanol metabolism in rats. Life Sciences 73, 933-946. 2003.

[35] Bruha, R., Dvorak, K., Petrtyl, J. Alcoholic liver disease. Word Journal of Hepatology 43, 81-90. 2012.

[36] Testino, G., Burra, P., Bonino, F., Piani, F., Sumberaz, A., Peressutti, R., Castiglione, A.G., Patussi, V., Fanucchi, T. Acute alcoholic hepatitis, end stage alcoholic liver disease and liver transplantation: An Italian position statement. Word Journal of Hepatology 2040, 14642-14651. 2014.

[37] Thkada, A., TSutsuxni, M.D. Iagnostic-criteria for alcoholic liverdisease. International Hepatology Communications 3, 63-69. 2005

[38] Hwang, C., Sinskey, A.J., Lodish, H.F. Oxidized redox state of glutathione in the endoplasmic-reticulum. Science 257, 1496-1502. 2012.

[39] Han, Y.O., Han, M.J., Park, S.H., Kim, D.H. Protective effects of kakkalide from Flos puerariae in ethanol-induced lethality and hepatic injury are dependent on its biotransformation by human intestinal microflora. Yakugaku zasshi 109(6), 424-431. 1989.

[40] Wang, L.Z., Yang, B., Du, X.Q., Yi, C. Optimisation of supercritical fluid extraction of flavonoids. Purification Technology 108, 737-741. 2008.

[41] Hanae I.Z.U., Megumi, S., Yasuko, M., Kuniyasu, G., Haruyuki, I S-adenosylmethionine (SAM)-accumulating aake aeast auppresses acute alcohol-induced liver injury in mice. Bioscience, Biotechnology, and Biochemistry 70, 2982-2989. 2006. 